\title{
Article
}

\section{ABG Assistant-Towards an Understanding of Complex Acid-Base Disorders}

\author{
Łukasz Gutowski $^{1}$ (D), Kaja Gutowska ${ }^{2}$ (D), Alicja Brożek ${ }^{1}$, Marcin Nowicki ${ }^{1}$ and $^{\text {Dorota Formanowicz }}{ }^{1, *(D)}$ \\ 1 Department of Medical Chemistry and Laboratory Medicine, Poznan University of Medical Sciences, \\ Rokietnicka 8, 60-806 Poznan, Poland; lgutowski@ump.edu.pl (Ł.G.); abrozek@ump.edu.pl (A.B.); \\ patogen@gmail.com (M.N.) \\ 2 Institute of Computing Science, Poznan University of Technology, Piotrowo 2, 60-965 Poznan, Poland; \\ Kaja.Gutowska@cs.put.poznan.pl \\ * Correspondence: doforman@ump.edu.pl
}

Citation: Gutowski, Ł.; Gutowska,

K.; Brożek, A.; Nowicki, M.;

Formanowicz, D. ABG

Assistant-Towards an

Understanding of Complex Acid-Base Disorders. J. Clin. Med. 2021, 10, 1516.

https://doi.org/10.3390/jcm 10071516

Academic Editor:

Olga Golubnitschaja

Received: 6 February 2021

Accepted: 2 April 2021

Published: 5 April 2021

Publisher's Note: MDPI stays neutral with regard to jurisdictional claims in published maps and institutional affiliations.

Copyright: (c) 2021 by the authors. Licensee MDPI, Basel, Switzerland. This article is an open access article distributed under the terms and conditions of the Creative Commons Attribution (CC BY) license (https:// creativecommons.org/licenses/by/ $4.0 /)$.
Abstract: The ability to diagnose acid-base imbalances correctly is essential for physicians and other healthcare workers. Despite its importance, it is often considered too complex and confusing. Although most people dealing with arterial blood gases (ABGs) do not usually have problems with acid-base disorder assessment, such an analysis is also carried out by other healthcare workers for whom this can be a challenging task. Many aspects may be problematic, partly due to multiple data analysis methods and no definitive statement on which one is better. According to our survey, the correctness of arterial blood gas analysis is unsatisfactory, especially in mixed disorders, which do not always manifest an obvious set of symptoms. Therefore, ABG parameters can be used as an established biomarker panel, which is considered to be a powerful tool for personalized medicine. Moreover, using different approaches to analyze acid-base disorders can lead to varying diagnoses in some cases. Because of these problems, we developed a mobile application that can spot diagnostic differences by taking into account physiological and chemical approaches, including their variants, with a corrected anion gap. The proposed application is characterized by a high percentage of correct analyses and can be an essential aid for diagnosing acid-base disturbances.

Keywords: arterial blood gas; acid-base; mixed disorders; ABG algorithm; corrected AG; evaluation of acid-base disorders; acidosis; alkalosis; prediction; diagnostics; personalized patient profiling; ABG application

\section{Introduction}

Blood gas analysis is an essential diagnostic tool in emergency departments and for clinical management under many conditions. Most often arterial blood is used for such analysis. However, venous blood gas (VBG) is sometimes analyzed because of infection at the insertion site or inadequate collateral circulation of extremities, In some specific clinical conditions, VBG can even be interpreted as interchangeable with arterial blood gas $(\mathrm{ABG})$ [1]. Arterial blood gas (ABG) analysis gives essential information about the patient's oxygenation status and Acid-Base balance. Further analysis requires much more data: electrolytes, lactate, glucose, osmolality, creatinine, and urine. However, even limiting the analyses only to the data obtained from ABGs causes difficulties for medical staff.

The problem of incorrect diagnosis of Acid-Base disorders starts at the universities. Different approaches and equations for secondary responses are taught at various universities because there is no agreement on which ABG analysis approach gives the best results [2,3]. Additionally, even within particular approaches, the terminology is not standardized. Despite the growing need for standardization and the establishment of appropriate standards [4] there is no consensus on ABG analysis or the teaching of it, which leads to difficulties in further learning. A student who has been taught a specific ABG analysis approach, while trying to expand his or her knowledge, collides with different 
terminology and approaches to the topic and has to spend much more time comprehending the differences and similarities among the other methods. If a physician starts working in a place where ABG is often analyzed, he or she adapts to the particular approach and terminology. With extended practice, such a person usually uses all possible analysis methods interchangeably and does not have any problems with terminology, such as when exchanging information about the case with other hospital staff. However, in practice, blood gases are rarely analyzed, so these skills are not intensively developed. For these healthcare workers, whether they be physicians, medical laboratory scientists, or paramedics, programs that help analyze patient results can be useful.

As mentioned above, complications, like multiple secondary-response equations, can lead to different diagnoses. Moreover, the analysis of mixed disorders, accompanied by an increasing number of coexisting disturbances, carries with it a higher risk of error. Because the mentioned equations are not accurate, they raise many concerns [5]. Similar reservations apply to the ratio between the serum anion gap (AG) change and the change in the bicarbonate $\left(\mathrm{HCO}_{3}{ }^{-}\right)$concentration $\left(\triangle \mathrm{AG} / \Delta \mathrm{HCO}_{3}{ }^{-}\right.$ratio) predictability, which depends on the factor causing the disorder and can be a false positive or negative [4,6-9].

The use of the AG enables a more precise analysis of the metabolic acidosis causes. Because AG precision is limited, Figge et al. [9] proposed adding the influence of hypoor hyperalbuminemia into the AG calculations. However, the analyzers do not calculate the corrected anion gap (AGc), so healthcare workers have to do this by themselves. Thus, when analyzing $A B G$, it is necessary to perform many calculations, often in a short time. It can be a cumbersome task and the cause of many mistakes.

Given the issues considered, we decided to develop a mobile application that not only analyzes data and checks its correctness but also compares the compatibility of diagnoses in four ways: (1) using the physiological (Boston) approach, (2) the physiological approach with the corrected anion gap, (3) the chemical (Copenhagen) approach, and (4) the chemical approach with the AGc [10-13]. The summary of these analyses is intended to show whether the diagnosis, previously made by the medics, is confirmed or if the patient's results are in a so-called grey area, which means that he can be diagnosed differently depending on the concept used. In this case, a signal was given that special attention should be paid while analyzing such a patient.

The application can be downloaded free of charge from the Google Play Store website [14], and its source code is available at GitHub [15]. Although programs supporting the analysis of Acid-Base disorders are not a new idea [16,17], in recent years we have witnessed the development of ABG analysis approaches [10-12,18-20] and technological progress; hence, we propose our ABG Assistant. Our application uses newer compensation formulas, anion gap ranges adapted to modern analyzers, and appropriate AG correction depending on the albumin concentration change. The developed program is based on existing ABG analysis algorithms; however, it has been improved by sets of parameters causing ambiguous diagnoses. Additionally, a function analyzing mixed disorders with less noticeable metabolic acidosis and unified division of disorders due to the value of the $\Delta \mathrm{AG} / \Delta \mathrm{HCO}_{3}{ }^{-}$ratio was introduced.

Since most people use smartphones daily, our program has been written in the Java programming language as an application for the Android system.

\section{Materials and Methods}

\subsection{Description of the Application}

The activities package contains six activities corresponding to the adequate application windows. The activity responsible for data entry also includes the code's main partanalyzing the entered parameters. This activity is described in more detail in Section 2.2, "The Algorithm". After performing the analyses using particular approaches, the results were transferred to the activity responsible for displaying the results. There, the compliance of the diagnosis was calculated. If the application finds that any of the approaches were not performed, it informs the user why it happened, which data was not entered. 
For the application's proper functioning, a mobile device with a minimum screen resolution of $720 \times 1280 \mathrm{px}$, equipped with Android version 5.0 or later, is required. The program consists of six windows. The first main window has three buttons: "data input", "caution", and "help" (Figure 1). The "caution" button leads to a window where the user is warned about the restrictions on using the application. First of all, the diagnosis should be based on comparing the patient's clinical condition and history with laboratory resultsone cannot rely solely on ABG Assistant analysis. Another button-"help" leads to a window where the application's basic operating principles are described. The "data input" button leads to the central part of the program. After clicking on it, a list of parameters that can be entered, along with the appropriate units, is displayed. The program has been designed to analyze results based on four possible variants simultaneously; however, some parameters do not have to be entered; without them, the program will analyze data using fewer concepts. The program was intended to work with standardized parameters, like standard $\mathrm{HCO}_{3}{ }^{-}\left(\mathrm{sHCO}_{3}{ }^{-}\right)$and Standard Base Excess (SBE). However, it is not possible to obtain standardized parameters for every blood gas analyzer. Even though the use of actual $\mathrm{HCO}_{3}{ }^{-}\left(\mathrm{aHCO}_{3}{ }^{-}\right)$might be misleading in respiratory disorders, in many cases it is still used regularly, so actual $\mathrm{HCO}_{3}{ }^{-}$may be used for $\mathrm{sHCO}_{3}{ }^{-}$in the main part of the application. The program always needs $\mathrm{pH}, \mathrm{sHCO}_{3}{ }^{-}$, partial pressure of carbon dioxide $\left(\mathrm{PaCO}_{2}\right)$, and an $\mathrm{AG}$ to run. Without albumin $(\mathrm{Alb})$, the program will not correct the anion gap, providing results for 2 out of 4 available methods. If the user does not enter SBE, the program will calculate it based on $\mathrm{pH}$ and $\mathrm{aHCO}_{3}{ }^{-}$(if provided). However, due to the multitude of formulas for SBE $[13,21,22]$, the data may not be identical to those the ABG analyzer would give. After clicking the "calculate" button, the program will open the window with analyses that could be carried out using the entered data. Information describing how many approaches have been used is displayed at the top of the screen, indicating the results' conformity. Below are the results of the particular methods. If a user does not enter some of the parameters, the corresponding information is displayed. The application gives a preliminary diagnosis of Acid-Base imbalance by determining if it is acute, chronic, simple, or complex. Users are informed if the entered ABG results are incorrect. The program warns if the difference between the entered and calculated $\mathrm{pH}$ is higher than 0.02. It also displays a report stating that the entered data are incorrect if the difference is greater than 0.1. Warnings are also shown for extreme values of entered parameters, which indicates false data. The user can get additional information to help make a diagnosis by clicking on the "information" button. It redirects to a window where the most common causes of Acid-Base disorders are listed. 


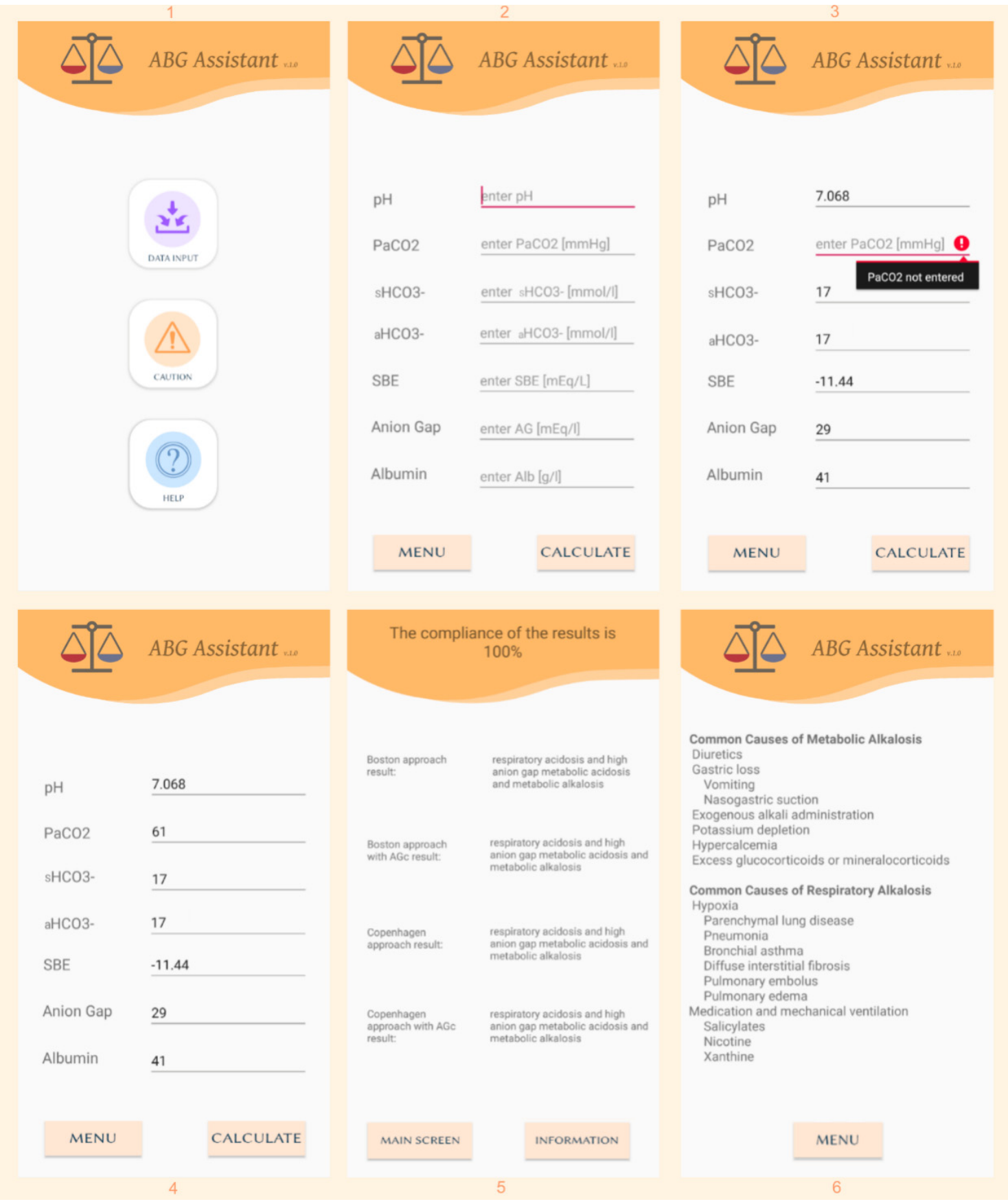

Figure 1. The individual screens of the ABG Assistant showing: (1) menu, (2) data input screen, (3) example warning if required data is not entered, (4) input of sample data, (5) results for previously entered data, (6) fragment of "information" screen.

\subsection{The Algorithm}

The main steps taken by the proposed algorithm are based on the works of Kenrick Berend et al. [11,12,20]; however, several changes have been introduced. Currently, there is no agreement as to what reference ranges should be used [4]. In our article we used the following ranges: $\mathrm{pH}: 7.34-7.44, \mathrm{PaCO}_{2}: 36-44 \mathrm{~mm} \mathrm{Hg}, \mathrm{HCO}_{3}{ }^{-}: 22-26 \mathrm{mmol} / \mathrm{L}, \mathrm{SBE}$ : -2-2 mmol/L, AG: 3-11 mEq/L, Alb 35-50 g/L. In contrast to other applications, our algorithm used a lower AG reference range because higher ones were characteristic for older analyzers. This modest change had a big impact on the calculations' correctness. According to research, the correct AG reference range should be 3-11 using the market- 
dominant ion-selective electrode (ISE) [22-24]. Certainly, the best solution would be to define a reference range for each patient individually in a healthy state, but this is rarely determined. Hence, the ranges provided by the laboratory are more often used. Some of the applications assessing Acid-Base disorders rely on entering $\mathrm{Na}$ and $\mathrm{Cl}$ values and calculating the AG instead of directly entering the AG value. However, this unnecessarily forces the user to enter further data as the formula for calculating the anion gap is almost always the same. The AG originates from the equation: $\mathrm{Na}^{+} \mathrm{K}^{+}+$unmeasured cations $=\mathrm{Cl}^{-}$ $+\mathrm{HCO}_{3}{ }^{-}+$unmeasured anions. Therefore, the formula using potassium was previously used: $\mathrm{AG}=\left(\mathrm{Na}^{+}+\mathrm{K}^{+}\right)-\left(\mathrm{Cl}^{-}+\mathrm{HCO}_{3}^{-}\right)$. Because the normal potassium reference range is low, the formula has been simplified to $\mathrm{AG}=\mathrm{Na}^{+}-\left(\mathrm{Cl}^{-}+\mathrm{HCO}_{3}{ }^{-}\right)$. Most of the studies analyzing the AG refer to this formula. Therefore, for the final analysis there is no difference whether the application allows users to enter the equation's components or uses an already calculated AG-its value is still the same.

The next step is calculating the AGc. Correction of the AG is calculated according to the equation: $\mathrm{AGc}=$ observed anion gap $+0.25 \times$ (normal albumin concentration observed albumin concentration) based on publication [10]. Other programs often use data in the form of integers for all values or floating-point numbers only for $\mathrm{pH}[25,26]$, thus limiting the accuracy of the analysis.

Our application was designed to enter the SBE value obtained from the ABG analyzer. However if the SBE is not given, the program estimates it based on aHCO3- and $\mathrm{pH}$ using the van Slyke equation: $0.9287 \times\left(\mathrm{HCO}_{3}{ }^{-}-24.4+14.83 \times(\mathrm{pH}-7.4)\right)$ [1]. The program checks the entered parameters' correctness individually and their combined compliance with the Henderson-Hasselbalch equation. The cases we analyzed usually did not exceed the difference between the measured and calculated $\mathrm{pH}$ by more than 0.015; however, different ABG analyzers use different measurement methods and formulas for calculating parameters, and this difference may increase, especially in severe clinical cases [27]. Therefore, two restrictions have been introduced: (1) exceeding the difference of 0.02 will trigger a notification that the result may be incorrect, and (2) exceeding the difference by 0.1 , will cause the program to display information about incorrect results. The compensation formulas for the physiological method were taken from [19,20] and from [11] for the chemical method. According to the prevailing hypothesis, no disturbance can be fully compensated for; all disorders with correct $\mathrm{pH}$ are classified as mixed disorders [12,28]. Instead of the $\Delta-\Delta$ gap used in the work of Berend et al., the proposed algorithm uses the $\triangle \mathrm{AG} / \triangle \mathrm{HCO}-$ ratio. If metabolic acidosis is detected, the $\triangle \mathrm{AG} / \mathrm{HCO}_{3}{ }^{-}$ratio is used as appropriate for the reference ranges $(\mathrm{AG}-7) /\left(24-\mathrm{HCO}_{3}{ }^{-}\right)$. When the $\mathrm{AG}$ is equal to or greater than $25 \mathrm{mEq} / \mathrm{L}$, the program warns the user to consider the presence of additional disorder. When the AG is equal to or greater than $30 \mathrm{mEq} / \mathrm{L}$, there is the certainty of additional high AG metabolic acidosis [29]. In both cases, the $\triangle \mathrm{AG} / \Delta \mathrm{HCO}_{3}{ }^{-}$ratio is then checked. There is a lot of controversy about the values at which the $\triangle \mathrm{AG} / \Delta \mathrm{HCO}_{3}{ }^{-}$ ratio indicates an additional disorder [6,9]. Some authors claimed that the $\triangle \mathrm{AG} / \Delta \mathrm{HCO}_{3}{ }^{-}$ ratio in high anion gap metabolic acidosis should be exactly equal to 1 . Greater than 1 would indicate additional metabolic alkalosis; below 1, an additional, normal anion gap metabolic acidosis. Nevertheless, this approach was poorly compatible with many disorders, especially lactic acidosis [6]. Besides, it should be noted that the $\triangle \mathrm{AG} / \Delta \mathrm{HCO}_{3}{ }^{-}$ ratio gives many results inconsistent with the actual diseases [9]. Therefore we used the following division for $\triangle \mathrm{AG} / \Delta \mathrm{HCO}_{3}{ }^{-}$:

- $<0.8$ indicates high anion gap metabolic acidosis together with possible normal anion gap metabolic acidosis;

- $\quad 0.8-1.2$ indicates high anion gap metabolic acidosis;

- 1.2-2 indicates high anion gap metabolic acidosis but probably not together with metabolic alkalosis;

- $\quad>2$ indicates high anion gap metabolic acidosis together with metabolic alkalosis.

Three examples are provided to explain how the algorithm works. The data from Table 1 and an example of correct results were used for the considerations. 
Table 1. Comparison of results from literature and application based on the same data.

\begin{tabular}{|c|c|c|c|c|c|c|c|c|}
\hline & \multirow{2}{*}{\multicolumn{2}{|c|}{ Cases }} & \multicolumn{6}{|c|}{ Analyzed Parameters } \\
\hline & & & $\mathrm{pH}$ & $\begin{array}{c}\mathrm{PaCO}_{2} \\
(\mathrm{~mm} \mathrm{Hg})\end{array}$ & $\begin{array}{l}\mathrm{HCO}_{3}^{-} \\
(\mathrm{mmol} / \mathrm{L})\end{array}$ & $\begin{array}{c}\mathrm{SBE} \\
(\mathrm{mmol} / \mathrm{L})\end{array}$ & $\underset{(\mathrm{mEq} / \mathrm{L})}{\mathrm{AG}}$ & $\begin{array}{l}\text { Alb } \\
(g / L)\end{array}$ \\
\hline \multirow{4}{*}{ No 1} & & values: & 7.39 & 39 & 22 & - & 19 & - \\
\hline & \multicolumn{2}{|c|}{ publication diagnosis: } & \multicolumn{6}{|c|}{ metabolic acidosis and metabolic alkalosis } \\
\hline & \multirow{2}{*}{$\begin{array}{l}\text { application } \\
\text { diagnosis: }\end{array}$} & physiological approach & \multicolumn{6}{|c|}{ high anion gap metabolic acidosis and metabolic alkalosis } \\
\hline & & chemical approach & \multicolumn{6}{|c|}{ high anion gap metabolic acidosis and metabolic alkalosis } \\
\hline \multirow{4}{*}{$\begin{array}{c}\text { No } \\
2\end{array}$} & & values: & 7.41 & 41 & 24 & - & 19 & - \\
\hline & \multicolumn{2}{|c|}{ publication diagnosis: } & \multicolumn{6}{|c|}{ metabolic acidosis and respiratory alkalosis } \\
\hline & \multirow{2}{*}{$\begin{array}{l}\text { application } \\
\text { diagnosis: }\end{array}$} & physiological approach & \multicolumn{6}{|c|}{ high anion gap metabolic acidosis and metabolic alkalosis } \\
\hline & & chemical approach & \multicolumn{6}{|c|}{ high anion gap metabolic acidosis and metabolic alkalosis } \\
\hline \multirow{4}{*}{$\begin{array}{c}\text { No } \\
3\end{array}$} & & values: & 7.36 & 22 & 11 & - & 25 & - \\
\hline & pub & ation diagnosis: & & & lic acidosis & respiratory & & \\
\hline & \multirow{2}{*}{$\begin{array}{l}\text { application } \\
\text { diagnosis: }\end{array}$} & physiological approach & \multicolumn{6}{|c|}{$\begin{array}{l}\text { respiratory alkalosis and high anion gap metabolic acidosis, possible additional } \\
\text { metabolic alkalosis }\end{array}$} \\
\hline & & chemical approach & \multicolumn{6}{|c|}{$\begin{array}{l}\text { respiratory alkalosis and high anion gap metabolic acidosis, possible additional } \\
\text { metabolic alkalosis }\end{array}$} \\
\hline \multirow{4}{*}{$\begin{array}{c}\text { No } \\
4\end{array}$} & & values: & 7.27 & 44 & 19 & - & 16 & - \\
\hline & pub & ation diagnosis: & & & lic acidosis & respiratory & & \\
\hline & \multirow{2}{*}{$\begin{array}{l}\text { application } \\
\text { diagnosis: }\end{array}$} & physiological approach & \multicolumn{6}{|c|}{$\begin{array}{l}\text { high anion gap metabolic acidosis and respiratory acidosis, possible additional metabolic } \\
\text { alkalosis }\end{array}$} \\
\hline & & chemical approach & \multicolumn{6}{|c|}{$\begin{array}{l}\text { high anion gap metabolic acidosis and respiratory acidosis, possible additional metabolic } \\
\text { alkalosis }\end{array}$} \\
\hline \multirow{4}{*}{$\begin{array}{c}\text { No } \\
5\end{array}$} & & values: & 7.6 & 45 & 51 & - & 14 & - \\
\hline & \multicolumn{2}{|c|}{ publication diagnosis: } & \multicolumn{6}{|c|}{ metabolic alkalosis and respiratory alkalosis } \\
\hline & application & physiological approach & & & ic alkalosis & respiratory & & \\
\hline & diagnosis: & chemical approach & & & ic alkalosis & respiratory & & \\
\hline & & values: & 7.42 & 59 & 36 & - & 7 & - \\
\hline No & pub & ation diagnosis: & & & lic alkalosis & respiratory & & \\
\hline 6 & application & physiological approach & & & ory acidosis & metabolic a & & \\
\hline & & chemical approach & & & ory acidosis & metabolic a & & \\
\hline & & values: & 7.47 & 23 & 16 & - & 44 & - \\
\hline No & pub & ation diagnosis: & chronic & iratory alkal & nigh anion $\mathrm{g}$ & netabolic aci & and metab & alkalosis. \\
\hline 7 & application & physiological approach & chronic & iratory alka & high anion $g$ & netabolic aci & and metab & alkalosis \\
\hline & & chemical approach & chronic & iratory alka & high anion $g$ & netabolic aci & and metal & alkalosis \\
\hline & & values: & 7.01 & 26 & 6 & - & 43 & - \\
\hline & pub & ation diagnosis: & hig & on gap meta & acidosis, re & tory acidosi & metabolic & alosis \\
\hline $\begin{array}{c}\text { No } \\
8\end{array}$ & application & physiological approach & high an & ap metaboli & $\begin{array}{r}\text { osis and res } \\
\text { al }\end{array}$ & $\begin{array}{l}\text { ory acidosis } \\
\text { sis }\end{array}$ & ible additic & netabolic \\
\hline & & chemical approach & high ar & ap metaboli & $\begin{array}{r}\text { osis and res } \\
\text { al }\end{array}$ & $\begin{array}{l}\text { ory acidosis } \\
\text { is }\end{array}$ & ible additic & metabolic \\
\hline & & values: & 7.06 & 28 & 8 & - & 10 & 23 \\
\hline & pub & ation diagnosis: & & high anior & metabolic a & sis and resp & $\mathrm{y}$ acidosis & \\
\hline & & physiological approach & & normal ani & p metabolic & osis and res & bry acidosis & \\
\hline $\begin{array}{l}\text { No } \\
9\end{array}$ & & $\begin{array}{c}\text { physiological approach } \\
\text { with AGc }\end{array}$ & high ar & gap metabol & $\begin{array}{l}\text { dosis and re } \\
\text { anion gap } \mathrm{m}\end{array}$ & $\begin{array}{l}\text { tory acidos } \\
\text { olic acidosi }\end{array}$ & ssible addit & l normal \\
\hline & diagnosis: & chemical approach & & normal ani & p metabolic & osis and res & ry acidosi & \\
\hline & & $\begin{array}{c}\text { chemical approach with } \\
\text { AGc }\end{array}$ & high a & gap metabol & $\begin{array}{l}\text { dosis and re } \\
\text { anion gap } m\end{array}$ & $\begin{array}{l}\text { tory acidos } \\
\text { olic acidosis }\end{array}$ & ssible addit & 1 normal \\
\hline
\end{tabular}


(1) $\mathrm{pH}, 7.4 ; \mathrm{PaCO}_{2}, 40 \mathrm{~mm} \mathrm{Hg} ; \mathrm{HCO}_{3}{ }^{-}, 24 \mathrm{mEq} / \mathrm{L} ; \mathrm{SBE}, 0 ; \mathrm{AG}, 11 \mathrm{mEq} / \mathrm{L}(\mathrm{Na}, 140 \mathrm{mEq} / \mathrm{L}$; $\mathrm{Cl}, 105 \mathrm{mEq} / \mathrm{L}) ; \mathrm{Alb}, 40 \mathrm{~g} / \mathrm{L}$.

(a) The entered data is analyzed. Based on the AG and the albumin, the AGc is calculated. The amount of data entered permits the use of the four approaches. For such data, all four methods are analyzed in a similar way:

(b) The algorithm checks the consistency of the entered data. There are no noticeable errors.

(c) The $\mathrm{pH}$ is checked. It is within the reference range.

(d) $\mathrm{PaCO}_{2}$ and $\mathrm{HCO}_{3}{ }^{-}$are checked by the methods using the physiological approach, and $\mathrm{PaCO}_{2}$ and SBE are examined using the chemical approach. All data are within reference ranges. In this step, rare cases of mixed disturbances and measurement errors are excluded (e.g., $\mathrm{HCO}_{3}{ }^{-}=40$ while the rest of the parameters are within normal limits).

(e) AG is checked. It is within the reference range. Because all of the values were within the reference ranges, and the algorithm did not find any abnormalities in the entered data, the application will display the result: "correct results" in the fields corresponding to all four approaches and above them: "The compliance of the results is $100 \% . "$

(2) $\mathrm{pH}, 7.6 ; \mathrm{PaCO}_{2}, 45 \mathrm{~mm} \mathrm{Hg} ; \mathrm{HCO}_{3}{ }^{-}, 51 \mathrm{mEq} / \mathrm{L} ; \mathrm{AG}, 14 \mathrm{mEq} / \mathrm{L}$.

(a) The entered data is analyzed. If the user assumes that the $\mathrm{SHCO}_{3}{ }^{-}$and $\mathrm{aHCO}_{3}$ values are the same and enters these into the application, the SBE will be calculated. The application will use two approaches-physiological and chemical. Otherwise, the amount of data entered allows using a physiological approach.

(b) The algorithm checks the consistency of the entered data. There are no noticeable errors.

(c) The $\mathrm{pH}$ is checked. The value exceeds 7.44, which indicates alkalosis.

(d) $\mathrm{PaCO}_{2}$ and $\mathrm{HCO}_{3}{ }^{-}$are checked by the method using a physiological approach, and $\mathrm{PaCO}_{2}$ and SBE are examined using the chemical approach. $\mathrm{PaCO}_{2}$ is above $36 \mathrm{mmHg}$; hence the program will check to. See if metabolic alkalosis is present. Then the $\mathrm{HCO}_{3}{ }^{-}$is checked using a physiological approach, and SBE is checked using a chemical approach. These values are not too low, so there are no errors or mistypes (e.g., a value of $\mathrm{HCO}_{3}{ }^{-}$of $10 \mathrm{mmol} / \mathrm{L}$ or SBE of -15 would not be not possible given the $\mathrm{pH} / \mathrm{PaCO}_{2}$ parameters and would indicate erroneous data).

(e) The algorithm checks the correct range of the secondary response to metabolic alkalosis. In a physiological approach, according to the formula $\mathrm{PaCO}_{2}=0.7 \times$ $\left(\mathrm{HCO}_{3}{ }^{-}-24\right)+40 \pm 2 \mathrm{~mm} \mathrm{Hg}$. The $\mathrm{PaCO}_{2}$ should therefore be in the range of 56.9-60.9 mm Hg. Since the $\mathrm{PaCO}_{2}$ value is much lower than expected, there is also respiratory alkalosis. The $\mathrm{PaCO}_{2}$ value differs from the calculated one by more than $5 \%$-application displays the message: "metabolic alkalosis and respiratory alkalosis". However, if the $\mathrm{PaCO}_{2}$ value differs from the calculated one by less than $5 \%$, instead of the mentioned response, the application would display the message: "metabolic alkalosis, probably with respiratory acidosis". In a chemical approach SBE is calculated according to the formula: SBE = $0.9287 \times\left(\mathrm{HCO}_{3}{ }^{-}-24.4+14.83 \times(\mathrm{pH}-7.4)\right)$ [20] equals to 27,458 .

(f) According to the formula $\triangle \mathrm{PaCO}_{2}=0.6 \times \mathrm{SBE} \mathrm{mm} \mathrm{Hg}$ [13]. $\mathrm{PaCO}_{2}$ should be equal to 56.475. Since the $\mathrm{PaCO}_{2}$ value is much lower than expected, there is also respiratory alkalosis. The $\mathrm{PaCO}_{2}$ value differs from the calculated one by more than $5 \%$; therefore, the application displays the message: "metabolic alkalosis and respiratory alkalosis". However, if the $\mathrm{PaCO}_{2}$ value differs from the calculated one by less than $5 \%$, instead of the mentioned response, the application would display the message: "metabolic alkalosis, probably with respiratory acidosis". Although the AG is elevated, such fluctuations 
are possible with this type of disorder and are not the basis for suspecting the presence of metabolic acidosis. However, if the AG exceeds $25 \mathrm{mEq} / \mathrm{L}$, the application informs the user that another disorder should be considered. When the AG exceeds $30 \mathrm{mEq} / \mathrm{L}$, the application informs the user about an additional disorder.

(g) Because the entered values made it possible to analyze the results with the use of 2 approaches, and the algorithm did not find any abnormalities in the data, the application will display the result: "metabolic alkalosis and respiratory alkalosis" in the fields corresponding to both of these approaches, and above them: "Comparing two approaches. The compliance of the results is $100 \%$ ".

(3) $\mathrm{pH}, 7.06 ; \mathrm{PaCO}_{2}, 28 \mathrm{~mm} \mathrm{Hg} ; \mathrm{HCO}_{3}{ }^{-}, 8 \mathrm{mEq} / \mathrm{L} ; \mathrm{AG}, 10 \mathrm{mEq} / \mathrm{L} ; \mathrm{Alb}, 23 \mathrm{~g} / \mathrm{L}$.

(a) The data is analyzed. AGc is calculated according to equation $\mathrm{AGc}=$ observed anion gap $+0.25 \times$ (normal albumin - observed albumin). If the user assumes that the values of $\mathrm{sHCO}_{3}{ }^{-}$and $\mathrm{aHCO}_{3}{ }^{-}$are the same, and enters these values into the application, the SBE will be calculated. The application will use two approaches-physiological and chemical. Otherwise, the amount of data entered permits the use of a physiological approach.

(b) The algorithm checks the consistency of the entered data. There are no noticeable errors.

(c) The $\mathrm{pH}$ is checked. The value is lower than 7.36, which indicates acidosis.

(d) $\mathrm{PaCO}_{2}$ and $\mathrm{HCO}_{3}{ }^{-}$are checked using a physiological approach, and $\mathrm{PaCO}_{2}$ and SBE are examined using a chemical approach. $\mathrm{PaCO}_{2}$ is below $44 \mathrm{~mm} \mathrm{Hg}$; hence the program will check if metabolic acidosis is present.

(e) The algorithm checks the correct range of the secondary response for metabolic acidosis in all approaches, analogous to the previous case. Since $\mathrm{PaCO}_{2}$ is higher than it should be, additional respiratory acidosis is expected.

(f) The value of the anion gap is checked:

- With the use of physiological and chemical approaches without AG correction, the $A G$ is $10 \mathrm{mEq} / \mathrm{L}$, so the algorithm diagnoses normal anion gap metabolic acidosis and respiratory acidosis.

- With the use of physiological and chemical approaches, the AGc equals $14.25 \mathrm{mEq} / \mathrm{L}$. When using the AGc, the algorithm diagnoses the presence of Hagma, not Nagma, as was suspected using the previous approach. In such an event, the $\Delta \mathrm{AG} / \Delta \mathrm{HCO}_{3}{ }^{-}$ratio must also be calculated. Its value is less than 0.8 [7]; hence, apart from the high anion gap metabolic acidosis and respiratory acidosis, normal anion gap metabolic acidosis is also suspected.

As the entered values made it possible to analyze the results using all approaches, the algorithm did not find any abnormalities in the entered data. The application displayed the result: "normal anion gap metabolic acidosis and respiratory acidosis" in the fields corresponding to the approaches without the AGc, and "high anion gap metabolic acidosis and respiratory acidosis, possible additional normal anion gap metabolic acidosis" in the areas corresponding to the approaches using the AGc. Above them, the program displayed, "The compliance of the results is 50\%."

A simplified scheme of the proposed algorithm is given in Figure 2. 


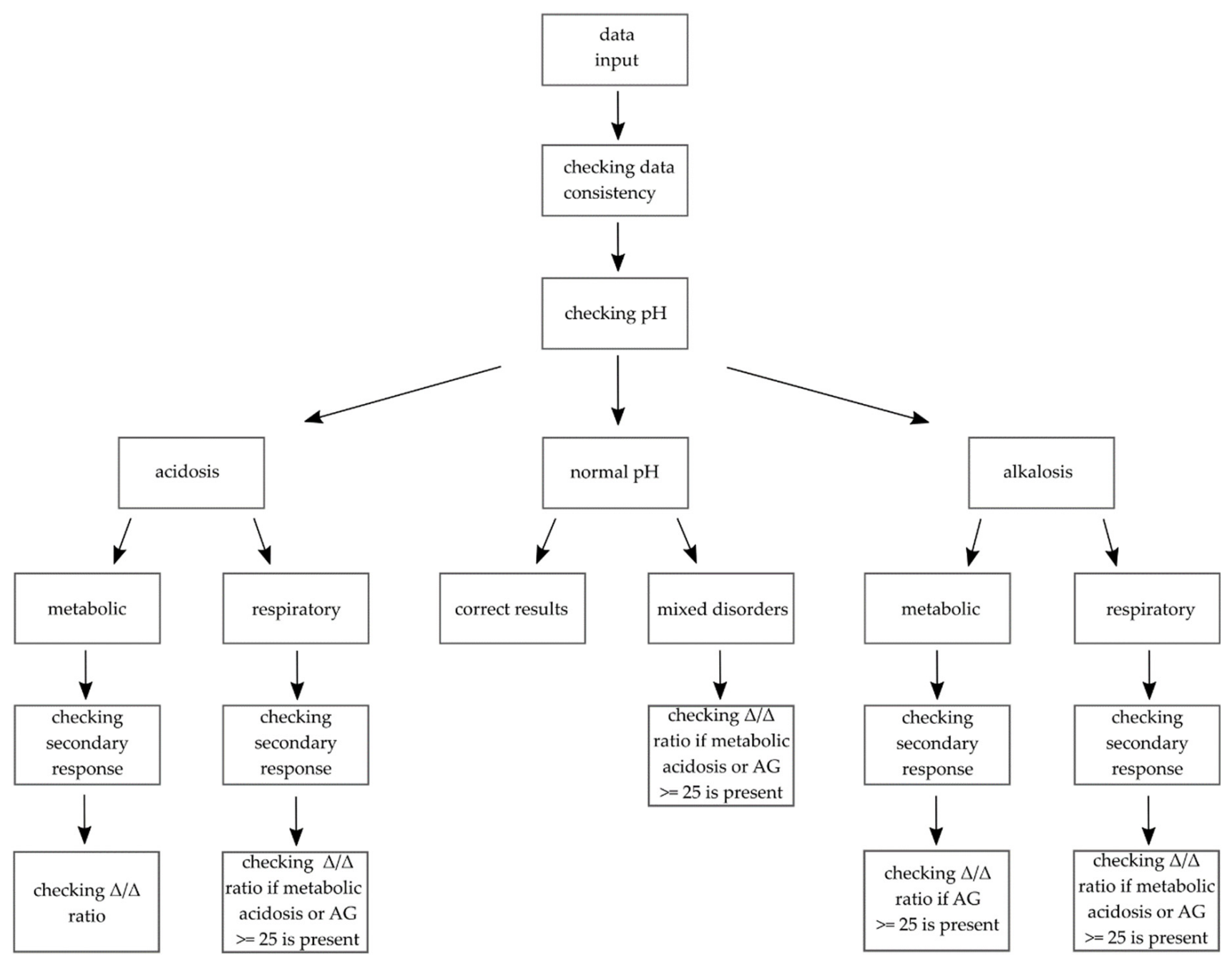

Figure 2. Simplified scheme of the algorithm. When the data is entered, the program analyses its consistency. If there are no obvious errors, the $\mathrm{pH}$ is checked. Next, based on the $\mathrm{PaCO}_{2}$ and $\mathrm{HCO}_{3}{ }^{-}$(or SBE in chemical approach), disorders are categorized as metabolic or respiratory. Then, the secondary response is checked. If there is a primary or additional high anion gap metabolic acidosis present, $\Delta / \Delta$ ratio is checked to detect possible triple disorders. $\Delta / \Delta$ ratio is also checked when the AG is equal to or higher than $25 \mathrm{mEq} / \mathrm{L}$.

\subsection{The Survey}

To assess the ability to analyze ABGs, we conducted a survey consisting of 10 questions. For each of them, the patient's results had to be analyzed to assess the Acid-Base disorder. In each question, diagnosing the disorder was limited to a selection from a comprehensive list of possible ones. The data for each case is presented in Table 2, together with the correct analysis. The reference ranges can differ depending on the laboratory or research. Therefore, at the beginning of the questionnaire, the reference ranges that the respondents were obligated to use were presented. These ranges are presented in Section 2.2, "The Algorithm". The introduction also included all the necessary formulas to estimate the correctness of a secondary response for a given disturbance, the HendersonHaselbalh equation, a simplified equation for calculating the hydrogen concentration, an $\Delta \mathrm{AG} / \Delta \mathrm{HCO}_{3}{ }^{-}$equation, and an equation for the AGc. Thanks to this, we were sure that we only assessed the respondents' ability to analyze the data and that the reference values and formulas used were identical and did not affect the respondents' answers. Respondents (healthcare workers: physicians, medical laboratory scientists, and paramedics) could have filled in a paper questionnaire or used the online form. 
Table 2. Characteristics of the cases which were analyzed in the survey.

\begin{tabular}{|c|c|c|c|c|c|c|c|}
\hline & & \multicolumn{6}{|c|}{ Parameters } \\
\hline \multicolumn{2}{|c|}{ Cases } & $\mathrm{pH}$ & $\begin{array}{c}\mathrm{PaCO}_{2} \\
(\mathrm{~mm} \mathrm{Hg})\end{array}$ & $\begin{array}{c}\mathrm{HCO}_{3}^{-} \\
(\mathrm{mmol} / \mathrm{L})\end{array}$ & $\begin{array}{c}\text { SBE } \\
(\mathrm{mmol} / \mathrm{L})\end{array}$ & $\underset{(\mathrm{mEg} / \mathrm{L})}{\mathrm{AG}}$ & $\begin{array}{l}\text { Alb } \\
(\mathrm{g} / \mathrm{L})\end{array}$ \\
\hline \multirow{2}{*}{$\begin{array}{c}\text { No } \\
1\end{array}$} & values: & 7.419 & 20 & 12.5 & -10.79 & 18.5 & 40 \\
\hline & disorder: & \multicolumn{6}{|c|}{ Respiratory alkalosis and high anion gap metabolic acidosis. } \\
\hline \multirow{2}{*}{$\begin{array}{c}\text { No } \\
2\end{array}$} & values: & 7.4 & 40 & 23.95 & -0.4 & 19 & 40 \\
\hline & disorder: & \multicolumn{6}{|c|}{ High anion gap metabolic acidosis and metabolic alkalosis. } \\
\hline \multirow{2}{*}{$\begin{array}{c}\text { No } \\
3\end{array}$} & values: & 7.423 & 19 & 12 & -11.2 & 34 & 40 \\
\hline & disorder: & \multicolumn{6}{|c|}{ Respiratory alkalosis, high anion gap metabolic acidosis and metabolic alkalosis. } \\
\hline \multirow{2}{*}{$\begin{array}{c}\text { No } \\
4\end{array}$} & values: & 7.068 & 61 & 17 & -11.44 & 29 & 41 \\
\hline & disorder: & \multicolumn{6}{|c|}{ Respiratory acidosis, high anion gap metabolic acidosis and metabolic alkalosis. } \\
\hline \multirow{2}{*}{$\begin{array}{c}\text { No } \\
5\end{array}$} & values: & 7.331 & 31.3 & 16 & -8.75 & 10.5 & 28 \\
\hline & disorder: & \multicolumn{6}{|c|}{ High anion gap metabolic acidosis. } \\
\hline \multirow{2}{*}{$\begin{array}{c}\text { No } \\
6\end{array}$} & values: & 7.438 & 38 & 18 & -5.42 & 17 & 46 \\
\hline & disorder: & \multicolumn{6}{|c|}{ Incorrect data. } \\
\hline \multirow{2}{*}{$\begin{array}{c}\text { No } \\
7\end{array}$} & values: & 7.638 & 28 & 29 & 7.55 & 10 & 37 \\
\hline & disorder: & \multicolumn{6}{|c|}{ Respiratory alkalosis and metabolic alkalosis. } \\
\hline \multirow{2}{*}{$\begin{array}{c}\text { No } \\
8\end{array}$} & values: & 7.522 & 27 & 21.4 & -1.11 & 11 & 43 \\
\hline & disorder: & \multicolumn{6}{|c|}{ Acute respiratory alkalosis. } \\
\hline \multirow{2}{*}{$\begin{array}{c}\text { No } \\
9\end{array}$} & values: & 7.042 & 82 & 21 & -8.09 & 8 & 39 \\
\hline & disorder: & \multicolumn{6}{|c|}{ Respiratory acidosis and normal anion gap metabolic acidosis. } \\
\hline \multirow{2}{*}{$\begin{array}{c}\text { No } \\
10\end{array}$} & values: & 7.308 & 52 & 25.2 & -0.52 & 9.6 & 38 \\
\hline & disorder: & \multicolumn{6}{|c|}{ Acute respiratory acidosis. } \\
\hline
\end{tabular}

The questionnaire could also have been completed by students of medical universities, provided that they had already passed ABG analysis training. Before proceeding with the diagnosis of disorders, respondents had to answer questions about their profession or education, professional experience, the approach they use daily, and how often they analyze ABG data.

\section{Results}

\subsection{Evaluation}

Evaluation of the application was based on a set of ABG tests taken from the medical literature [30] and 10 selected ABG disturbances, which were also used to compare the application and human accuracy of the diagnosis. According to the application's functionality, the proposed diagnoses of Acid-Base disorders were made using up to four methods: physiological, chemical and variants of these approaches using the AGc. The list of parameters and diagnoses used in the mentioned publication has been compared with the proposed application results and is included in Table 1. The following parameters have been taken into account: $\mathrm{pH}$, partial pressure of carbon dioxide $\left(\mathrm{PaCO}_{2}\right)$, bicarbonate $\left(\mathrm{HCO}_{3}{ }^{-}\right)$, standard base excess (SBE), Anion Gap (AG), and albumin (Alb).

In most cases, the program was consistent with the diagnosis or even more detailed although there were cases in the cited literature [30], where the diagnoses differed slightly. Each of these cases is listed below with an explanation of the difference in the approach to analysis:

Cases no. 1 and 2-the application gave more detailed results than the literature; it specified the type of metabolic acidosis. 
Case no. 3-in the publication, this case was diagnosed as metabolic acidosis and respiratory acidosis. As mentioned earlier, all diagnoses made solely based on the ABG results can differ depending on the formulas used. Our application also warned about the possibility of the co-occurrence of an additional disorder ("possible additional metabolic alkalosis") because the data gave results close to the limit value. If the results exceed the calculated compensation range but do not exceed it by $5 \%$, the application says that the values are close to the correct range; however, there is a possibility of the co-existence of an additional disorder.

Partial incompatibility occurred in cases no. 3, 4, and 9. In all these cases, the results were close to the cut-off value, so the program warned about the possibility of additional interference. In case no. 8, a similar situation occurred. Here, the results obtained from the application warned about "the possible additional metabolic alkalosis", but the cited diagnosis only mentioned the presence of "metabolic alkalosis".

Case no. 9. Here, the additional value of albumin concentration was given, allowing the use of the application's full functionality. In this way, the program used two additional methods that calculated the corrected anion gap, thanks to which the results were more precise than when taking into account only one of the methods. As a result, instead of merely obtaining information: "normal anion gap metabolic acidosis and respiratory acidosis," the application also displayed: "high anion gap metabolic acidosis and respiratory acidosis, possible additional normal anion gap metabolic acidosis."

\subsection{Comparison of the Interpretations of the Patients' Results Analyzed by Application and Human}

For determining whether the application would be beneficial for the healthcare workers, a survey was carried out. The questionnaire consisted of 10 cases and contained all necessary formulas and reference ranges needed to conduct the analysis. In all cases, the diagnosis made by using the physiological and chemical approaches was precisely the same. Diagnosis of the disorder had to be made using the included reference ranges and compensation equations and based on the data presented in Table 2. The reference ranges and formulas were consistent with those used by the application. The disorder's diagnosis was limited to its selection from the comprehensive list of possible ones found under every question. The questionnaire was completed by 62 volunteers: physicians (32.3\%), medical laboratory scientists (25.8\%), students of laboratory diagnostics (24.2\%), medical students $(14.5 \%)$, paramedics (3.2\%). On average, 50.16\% respondent answers were correct.

Not surprisingly, the percentage of correct answers increased with the declared frequency of analyzing ABG data in practice. Respondents performing analyses rarely or very rarely gave fewer correct answers than those who performed them often or very often (Figure 3). The same tendencies from the 1980s [16] were also shown in our survey although the ability to analyze triple disturbances was slightly higher than in the mentioned publication (Figure 4). The questionnaire also contained one case where the ABG data were incorrect-only $41.9 \%$ of respondents noticed this. All the cases shown in Table 2 were tested by application and gave accurate results; in case no. 5, the albumin level was very low, so the best results were displayed using approaches with corrected anion gap. 


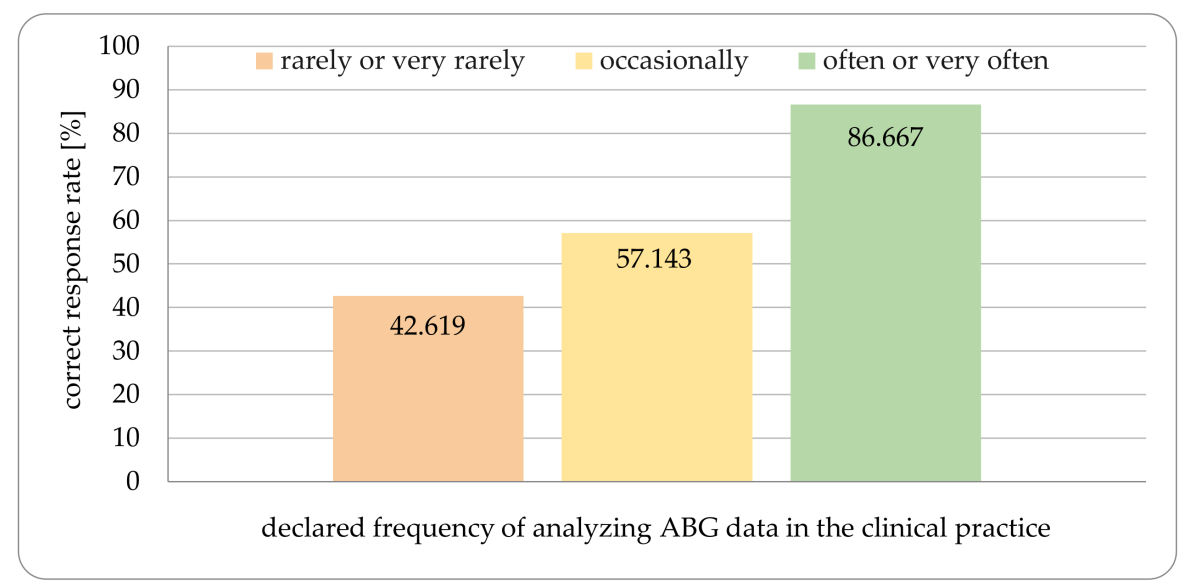

Figure 3. The matching of correct response rate with declared frequency of analyzing ABG data in the clinical practice.

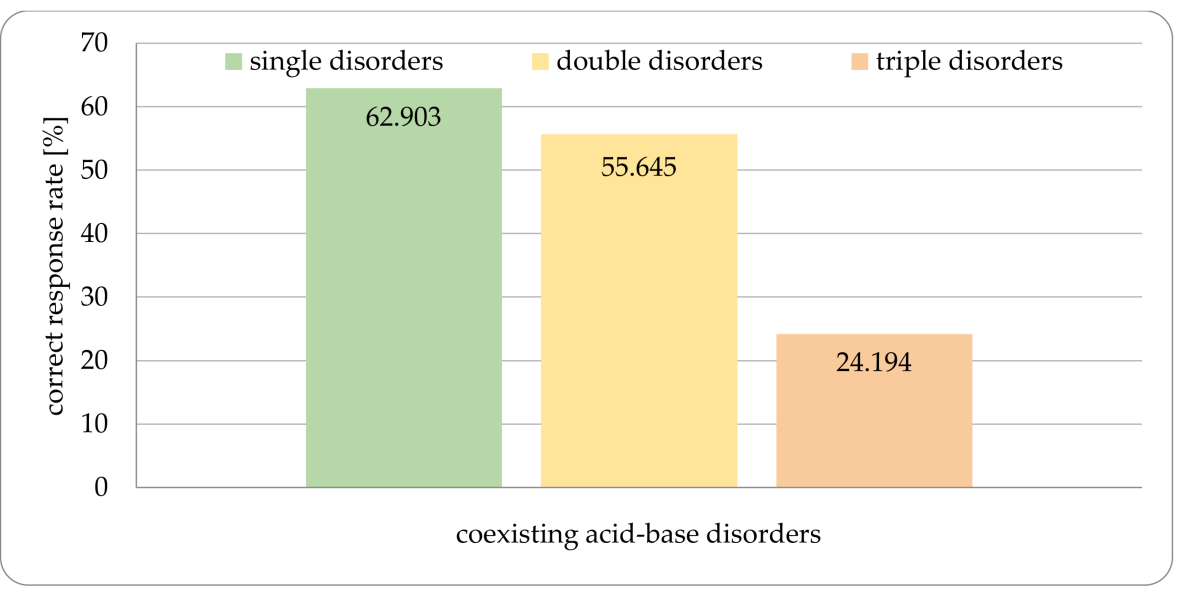

Figure 4. Comparison of correct response rate and number of coexisting Acid-Base disorders presented in the questionnaire.

\section{Discussion}

\subsection{Overview}

According to our survey results, people who do not analyze ABG daily are often mistaken in their diagnoses. The tool we created can be an excellent support for such people by speeding up confirmation of the analyzed data's accuracy and double-checking that the analysis was carried out correctly.

We believe that the ABG Assistant can be a valuable tool for healthcare workers. As our survey results showed, this application can be helpful, especially for people who rarely analyze ABG. Our program, which analyzes the entered data through many approaches, forces such people to analyze the data in depth. On the other hand, for people who deal with ABG analysis daily, this program will be a perfect tool for quickly checking their analyses. Instead of laboriously calculating the accuracy of ABG data using the HendersonHasselbalch formula, our application will show whether the results are consistent.

Additionally, by obtaining a different diagnosis, the user gets a clear signal that such a case needs deeper consideration and analyses where the difference in a patient's condition's assessment came from. Although the ABG Assistant is not flawless, it correctly analyses more cases than the compared applications and demonstrates educational potential. The user can compare Acid-Base disorder diagnosis with the one provided by the application. Moreover, it is not important whether the chemical or physiological method is used dailythis program is useful in both cases. We hope that our publication will also stimulate 
discussion on the quality of analyses performed by mobile applications that was initiated by Nicholson and Corbridge [31]

The Acid-Base disorder can be an adverse prognostic indicator. Although the detection of simple disorders is not a problem, according to our survey, the detection of mixed disorders is more difficult. They do not always manifest themselves in an obvious set of symptoms. Therefore, ABG parameters can be used as biomarkers. Disease entities in which Acid-Base disorders are an integral part of diagnostic criteria can serve as a good example. One of such examples is ketoacidosis. If it occurs with a simple disorder, the diagnosis is not a problem. However, in some cases, as in the ketoalkalosis the misdiagnosis of Acid-Base disorder translates into the risk of misdiagnosis of the underlying disease. This is why our application significantly increases predictability and thus fits into the Predictive, Preventive and Personalized Medicine (PPPM) ideology, to which increasing attention is being drawn [32-36].

Naturally, the analysis of the Acid-Base disorders is essential in diagnosing a multitude of cases such as systemic ischemia, infections of lungs, inflammations or cancer. It also affects the patient's treatment, for example, in birth asphyxia, where acidosis can alter the concentration of potassium in the blood [37].

\subsection{Comparison of Available Applications}

The automation of $A B G$ interpretation is not a new idea. The first programs helping in ABG analysis were created as early as the 1970s [16]. Nonetheless, since then there has been significant technological development: computing power, once only available on personal computers, has become widely available on smartphones, which are found in the majority of societies. Research into ABG analysis also has developed: concepts, reference ranges, formulas, and even analyzed parameters are changing. During application development, we tried to include the most modern Acid-Bases analysis approach possible and use the widespread availability of smartphones to create a new mobile tool. Naturally, many applications have been developed that try to introduce newer solutions; currently, one of the most used applications for ABG analysis is MD Calc [38]. However, in our opinion, it has some limitations. Firstly, it diagnoses using only bicarbonate, while our application permits the use of SBE, calculates SBE, or analyzes data simultaneously using bicarbonate and SBE. Another limitation is the need to enter the value of albumin to obtain the analysis. Sometimes the albumin test has not been performed, or the results will be available later. In such a scenario, our application allows ABGs to be analyzed using the available data without correcting the anion gap for the influence of Alb. Tracking the albumin correction's influence is also very simple in ABG Assistant as the analyses obtained by all methods are compiled on one card. However, the most important disadvantage of MD Calc is an incorrect analysis of some cases, which is a common problem among ABG evaluating applications, as noted by T. Nicholson [31]. The mentioned publication cites the case with the following parameters: $\mathrm{pH}, 7.4 ; \mathrm{PaCO}_{2}, 40 \mathrm{~mm} \mathrm{Hg} ; \mathrm{HCO}_{3}{ }^{-}, 24 \mathrm{mEq} / \mathrm{L}$; AG, $21(\mathrm{Na}, 145 \mathrm{meq} / \mathrm{L} ; \mathrm{Cl}, 100 \mathrm{meq} / \mathrm{L}) ; \mathrm{Alb}, 40 \mathrm{~g} / \mathrm{L}$. Regardless of the analysis methodphysiological, chemical, or physicochemical-evaluation should indicate high anion gap metabolic acidosis with metabolic alkalosis. The ABG Assistant proposes just such a diagnosis for the presented data. Unfortunately, the analysis by MD Calc gives "Primary Metabolic Alkalosis, with: Appropriately Compensated by Respiratory Acidosis". Even worse, it presents the same analysis for results that are within the reference ranges and do not represent any Acid-Base disturbance: $\mathrm{pH}, 7.4 ; \mathrm{PaCO}_{2}, 40 \mathrm{~mm} \mathrm{Hg} ; \mathrm{HCO}_{3}{ }^{-}, 24 \mathrm{mEq} / \mathrm{L}$; AG, 11 (Na, 140 meq/L; Cl, 105 meq/L); Alb, 40 g/L.

\subsection{Problematicity of Assessment}

As mentioned earlier, the diagnosis of ABG creates many problems; of course, triple disorders cause the most significant diagnostic difficulties. However, even necessary activities such as checking the correctness of results were performed by a small proportion of respondents. Similar conclusions can be drawn from Schreck et al. [16], so the trend 
continues despite the passage of more than 30 years. As one can see from our survey, people analyzing $A B G$ often or very often have interpreted most of the results correctly because of their experience. However, Acid-Base analysis is used by healthcare workers of various professions and specializations, including ones who use it less often, and for them, our application may have the highest value.

Unlike people, the application does not compare ABGs with a medical history and physical examination. Still, the program may point out possible solutions that a medical staff could have overlooked, even the presence of a complex disorder. Such analysis is carried out using a physiological and chemical approach, both with and without using a corrected anion gap. The use of many approaches to data analysis is beneficial because there is no consensus about which method is the best for analyzing ABGs. Some scientists try to emphasize the superiority of different approaches, while others ensure their comparability $[2,3,39]$. Many cases in which the analysis depends on used concepts and formulas can be mentioned. The following case may serve as an example:

pH: 7.05, $\mathrm{PaCO}_{2}: 15 \mathrm{mmHg}, \mathrm{sHCO}_{3}^{-}: 4 \mathrm{mmol} / \mathrm{L}, \mathrm{SBE}:-24 \mathrm{mmol} / \mathrm{L}, \mathrm{Alb} 20 \mathrm{~g} / \mathrm{L}, \mathrm{AG}$ $29 \mathrm{mEq} / \mathrm{L}$.

The developed algorithm returned the following results:

(a) physiological approach: high anion gap metabolic acidosis

(b) physiological approach with AGc: high anion gap metabolic acidosis, possible additional metabolic alkalosis.

(c) chemical approach: high anion gap metabolic acidosis, probably with respiratory alkalosis.

(d) chemical approach with AGc: high anion gap metabolic acidosis, probably with respiratory alkalosis, possible additional metabolic alkalosis.

As one can see, there is no match between the results of the analyses. Such an example emphasizes that many cases of Acid-Base disorders are challenging to analyze. Therefore, using only one approach for an ABG analysis can sometimes lead to a wrong diagnosis. In cases like this, our program displays information about the low compliance of the analyses, thus giving the physician a clear signal that such patients should be given additional attention when being diagnosed.

During the analysis of the results, an additional aspect is worth noticing: our application displayed the results using the word "probably". Indeed, an ABG analysis is complicated not only because of the multitude of formulas but also because of difficulties in confirming their correctness [4]. Therefore, the certainty of diagnosis decreases with the number of coexisting disturbances; the $\triangle \mathrm{AG} / \Delta \mathrm{HCO}_{3}{ }^{-}$ratio is also a parameter with many false-positive or negative results. Even in the $\mathrm{ABG}$ analysis literature, it is possible to spot vague statements like "actual $\mathrm{HCO}_{3}{ }^{-}$is almost like predicted" [40]. As one can notice, the formulation "almost" in the context of ABG analysis is too often overused as an indication of a confirmation of the hypothesis. Such results can and should be treated as uncertain when they are on the border of two solutions. To make the diagnosis of disorders more realistic in our program, we changed the display of non-obvious, borderline results. Such cases are displayed as "probable" if the result exceeds the calculated compensation range but does not exceed it by $5 \%$. The program gives the additional information that the result is less dependable and must be confirmed. The physician has to decide which option is more consistent with the patient's condition.

\subsection{Limitations}

Of course, the program we wrote has several restrictions. As mentioned earlier, the main one is the analysis of the ABG results without additional information about the patient's clinical condition. Although the most common causes of the underlying disorders are listed in the "information" panel. The second is the small number of analyzed parameters. Therefore, the application cannot recognize some diseases. It can easily cope with the analysis of Acid-Base disorders occurring during diabetic ketoacidosis (DKA) or DKA with normal $\mathrm{pH}$. Still, when the program analyses DKA with alkalemia—with a $\mathrm{pH}$ 
above 7.44 and AG lower than $25 \mathrm{mEq} / \mathrm{L}$, the program can display only metabolic alkalosis. A physician carefully analyzing such results can notice the possibility of metabolic alkalosis and coexisting high anion gap metabolic acidosis present in DKA with alkalemia [41]. Currently, no program meets all the requirements for an ABG analysis. In the future, however, we would like to create a new, more extensive tool to analyze more laboratory tests results concerning ketones, lactate, glucose, osmolality, creatinine, and urine, and possibility set personal reference ranges for each parameter. The use of individual reference ranges will allow for a more personalized analysis of the entered data and thus act in accordance with PPPM.

\section{Conclusions}

In medical practice, mobile applications and computer programs might not achieve as detailed analysis as that made by specialists for many more decades. An application cannot be a substitute for an accurate, complete diagnosis. Nevertheless, based on our survey results, healthcare workers who analyze blood gases less often in daily clinical work have considerable problems, especially when it comes to mixed disorders. Thus, our study group developed an application called "ABG Assistant" to aid healthcare workers in blood gas interpretation. We hope that it will have an impact on the progress of predictive diagnostics and personalized treatment. Using this application should help draw attention to aspects that some overworked specialists may not notice or forget about: diagnosing double and triple disorders, correcting the anion gap, and verifying data.

Author Contributions: Conceptualisation, Ł.G.; methodology, Ł.G.; software, Ł.G., K.G.; validation, Ł.G., K.G., A.B., and M.N.; formal analysis, Ł.G.; investigation, Ł.G.; writing-original draft preparation, Ł.G., K.G., A.B., M.N., and D.F.; writing-review and editing, Ł.G.; D.F.; visualisation, Ł.G.; supervision, D.F.; project administration, D.F.; funding acquisition, D.F. All authors have read and agreed to the published version of the manuscript.

Funding: This research has been supported by the statutory funds of Poznan University of Medical Sciences No. 502-01-22283690-08800.

Institutional Review Board Statement: The study was conducted according to the guidelines of the Declaration of Helsinki, and approved by the Ethics Committee of Poznan University of Medical Sciences. Protocol code 14/07, 4 January 2007.

Informed Consent Statement: Informed consent was obtained from all subjects involved in the study.

Data Availability Statement: The data presented in this study is contained within this article.

Conflicts of Interest: The authors declare no conflict of interest.

\section{References}

1. Schütz, N.; Roth, D.; Schwameis, M.; Röggla, M.; Domanovits, H. Can Venous Blood Gas Be Used as an Alternative to Arterial Blood Gas in Intubated Patients at Admission to the Emergency Department? A Retrospective Study. Open Access Emerg. Med. 2019, 11, 305-312. [CrossRef] [PubMed]

2. Kimura, S.; Shabsigh, M.; Morimatsu, H. Traditional approach versus Stewart approach for Acid-Base disorders: Inconsistent evidence. SAGE Open Med. 2018, 6, 6. [CrossRef]

3. Adrogué, H.J. Assessing Acid-Base disorders. Kidney Int. 2009, 76, 1239-1247. [CrossRef]

4. Berend, K. Acid-Base pathophysiology after 130 years: Confusing, irrational and controversial. J. Nephrol. 2012, 26, 254-265. [CrossRef] [PubMed]

5. Berend, K. Bedside rule secondary response in metabolic acid-base disorders is unreliable. J. Crit. Care 2013, 28, 1103. [CrossRef] [PubMed]

6. Adams, B.D.; Bonzani, T.A.; Hunter, C.J. The anion gap does not accurately screen for lactic acidosis in emergency department patients. Emerg. Med. J. 2006, 23, 179-182. [CrossRef]

7. Kraut, J.A.; Madias, N.E. Serum Anion Gap: Its Uses and Limitations in Clinical Medicine. Clin. J. Am. Soc. Nephrol. 2006, 2, 162-174. [CrossRef]

8. Reddy, P.; Mooridian, A.D. Clinical utility of anion gap in deciphering Acid-Base disorders. Int. J. Clin. Pract. 2009, 63, 1516-1525. [CrossRef] 
9. Rastegar, A. Use of the $\Delta \mathrm{AG} / \Delta \mathrm{HCO}$ - ratio in the diagnosis of mixed acid-base disorders. J. Am. Soc. Nephrol. 2007, 18, 2429-2431. [CrossRef] [PubMed]

10. Figge, J.; Jabor, A.; Kazda, A.; Fencl, V. Anion gap and hypoalbuminemia. Crit. Care Med. 1998, 26, 1807-1810. [CrossRef] [PubMed]

11. Berend, K.; de Vries, A.P.J.; Gans, R.O.B. Physiological Approach to Assessment of Acid-Base Disturbances. N. Engl. J. Med. 2014, 371, 1434-1445. [CrossRef]

12. Berend, K. Diagnostic Use of Base Excess in Acid-Base Disorders. N. Engl. J. Med. 2018, 378, 1419-1428. [CrossRef] [PubMed]

13. Berend, K.; Duits, A.J. The role of the clinical laboratory in diagnosing acid-base disorders. Crit. Rev. Clin. Lab. Sci. 2019, 56, 147-169. [CrossRef]

14. Available online: https://play.google.com/store/apps/details?id=com.lukaszgutowski.rkz_0_21 (accessed on 4 April 2021).

15. Available online: https://github.com/lukaszgutowski/ABG-Assistant.git (accessed on 4 April 2021).

16. Schreck, D.M.; Zacharias, D.; Grunau, C.F. Diagnosis of complex acid-base disorders: Physician performance versus the microcomputer. Ann. Emerg. Med. 1986, 15, 164-170. [CrossRef]

17. Goldberg, M.; Green, S.B.; Moss, M.L.; Marbach, C.B.; Garfinkel, D. Computer-based instruction and diagnosis of acid-base disorders: A systematic approach. JAMA 1973, 223, 269-275. [CrossRef]

18. Pincé, H.; Verberckmoes, R.; Willems, J. Computer aided interpretation of acid-base disorders. Int. J. Bio-Med. Comput. 1990, 25, 177-192. [CrossRef]

19. Narins, R.G.; Emmett, M. Simple and mixed acid-base disorders: A practical approach. Medicine 1980, 59, 161-187. [CrossRef] [PubMed]

20. Gilbert, H.C.; Vender, J.S. Arterial Blood Gas Monitoring. Crit. Care Clin. 1995, 11, 233-248. [CrossRef]

21. Park, M.; Taniguchi, L.U.; Noritomi, D.T.; Libório, A.B.; Maciel, A.T.; Cruz-Neto, L.M. Clinical utility of standard base excess in the diagnosis and interpretation of metabolic acidosis in critically ill patients. Braz. J. Med. Biol. Res. 2008, 41, 241-249.

22. Morgan, T.J.; Power, G.; Venkatesh, B.; Jones, M.A. Acid-Base Effects of a Bicarbonate-Balanced Priming Fluid during Cardiopulmonary Bypass: Comparison with Plasma-Lyte 148. A Randomised Single-Blinded Study. Anaesth. Intensiv. Care 2008, $36,822-829$. [CrossRef]

23. Sadjadi, S.-A.; Manalo, R.; Jaipaul, N.; McMillan, J. Ion-selective electrode and anion gap range: What should the anion gap be? Int. J. Nephrol. Renov. Dis. 2013, 6, 101-105. [CrossRef] [PubMed]

24. Salem, M.M.; Mujais, S.K. Gaps in the Anion Gap. Arch. Intern. Med. 1992, 152, 1625-1629. [CrossRef]

25. MedCalc: Acid-Base Calculator. Available online: http://www.medcalc.com/acidbase.html (accessed on 20 May 2020$).$

26. ABG Acid-Base Eval. Available online: https://play.google.com/store/apps/details?id=com.drstein.abgacid_baseeval\&hl=en (accessed on 20 May 2020).

27. Tanemoto, M.; Kimura, T.; Yamada, S.; Yokoyama, T.; Okazaki, Y. Difference in Bicarbonate Calculation Algorithm by Manufacturer Alters Diagnosis of Acid-Base Disorders. Ann. Biomed. Eng. 2019, 47, 2351-2352. [CrossRef]

28. Bruno, C.M.; Valenti, M. Acid-Base Disorders in Patients with Chronic Obstructive Pulmonary Disease: A Pathophysiological Review. J. Biomed. Biotechnol. 2012, 2012, 1-8. [CrossRef]

29. Yap, C.Y.; Aw, T.C. Arterial Blood Gases. Proc. Singap. Heal. 2011, 20, 227-235. [CrossRef]

30. Reddi, A.S. Mixed Acid-Base Disorders. In Fluid, Electrolyte and Acid-Base Disorders; Metzler, J.B., Ed.; Springer: Berlin/Heidelberg, Gremnay, 2017; pp. 449-462.

31. Nicholson, T.T.; Corbridge, T.C. Acids, Bases, and Apps: Primum Non Nocere. Ann. Am. Thorac. Soc. 2016, 13, 2277-2278. [CrossRef]

32. Ahluwalia, P.; Ahluwalia, M.; Vaibhav, K.; Mondal, A.; Sahajpal, N.; Islam, S.; Fulzele, S.; Kota, V.; Dhandapani, K.; Baban, B.; et al. Infections of the lung: A predictive, preventive and personalized perspective through the lens of evolution, the emergence of SARS-CoV-2 and its pathogenesis. EPMA J. 2020, 11, 581-601. [CrossRef]

33. Kou, F.; Zhu, C.; Wan, H.; Xue, F.; Wang, J.; Xiang, L.; Li, J. Endothelial progenitor cells as the target for cardiovascular disease prediction, personalized prevention, and treatments: Progressing beyond the state-of-the-art. EPMA J. 2020, 11, 629-643. [CrossRef] [PubMed]

34. Qian, S.; Golubnitschaja, O.; Zhan, X. Chronic inflammation: Key player and biomarker-set to predict and prevent cancer development and progression based on individualized patient profiles. EPMA J. 2019, 10, 365-381. [CrossRef] [PubMed]

35. Maturo, M.G.; Soligo, M.; Gibson, G.; Manni, L.; Nardini, C. The greater inflammatory pathway-High clinical potential by innovative predictive, preventive, and personalized medical approach. EPMA J. 2020, 11, 1-16. [CrossRef]

36. Polivka, J.; Pesta, M.; Rohan, V.; Celedova, L.; Mahajani, S.; Topolcan, O.; Golubnitschaja, O. Risks associated with the stroke predisposition at young age: Facts and hypotheses in light of individualized predictive and preventive approach. EPMA J. 2019, 10, 81-99. [CrossRef] [PubMed]

37. Thakur, J.; Bhatta, N.K.; Singh, R.R.; Poudel, P.; Lamsal, M.; Shakya, A. Prevalence of electrolyte disturbances in perinatal asphyxia: A prospective study. Ital. J. Pediatr. 2018, 44, 1-6. [CrossRef]

38. MDCalc Medical Calculator. Available online: https:// play.google.com/store/apps/details?id=com.mdaware.mdcalc\&hl=pl\& gl=US (accessed on 25 February 2021). 
39. Todorović, J.; Nešovic-Ostojić, J.; Milovanović, A.; Brkić, P.; Ille, M.; Čemerikić, D. The assessment of acid-base analysis: Comparison of the "traditional" and the "modern" approaches. Med. Glas. Off. Publ. Med. Assoc. Zenica-Doboj Canton Bosnia Herzeg. 2015, 12, 7-18.

40. Hasan, A. Handbook of Blood Gas/Acid-Base Interpretation; Springer Science and Business Media: London, UK, 2009.

41. Zonszein, J.; Baylor, P. Diabetic ketoacidosis with alkalemia-A review. West. J. Med. 1988, 149, 217-219. [PubMed] 